\title{
ANTI-INFLAMMATORY AND ANTIOXIDANT EFFECTS OF AN ETHANOLIC EXTRACT OF THE AERIAL PARTS OF HILLERIA LATIFOLIA (LAM.) H. WALT. (PHYTOLACCACEAE)
}

\section{W.K.M. Abotsi, G.K. Ainooson, E. Woode*}

\author{
Department of Pharmacology, Faculty of Pharmacy and Pharmaceutical Sciences, College of Health \\ Sciences, Kwame Nkrumah University of Science and technology, Kumasi, Ghana \\ *E-mail: ewoode.pharm@knust.edu.gh
}

\begin{abstract}
Various parts of the perennial herb Hilleria latifolia (Lam.) H. Walt. (Family: Phytolaccaceae) are used in Ghanaian traditional medicine for the treatment of several inflammatory-related disorders. The present study examined the anti-inflammatory effect of an ethanolic extract of the aerial parts of Hilleria latifolia (HLE) in acute and chronic inflammation models. Since free radicals and reactive oxygen species are implicated in inflammatory diseases, the antioxidant potential of HLE was also investigated in in vitro experimental models. HLE (10-300 mg kg ${ }^{-1}$, p.o.), either preemptively or curatively, significantly inhibited carrageenan-induced foot oedema in 7-day old chicks. Similarly, the NSAID diclofenac (10-100 mg kg-1, i.p.) and the steroidal anti-inflammatory agent dexamethasone $\left(0.3-3 \mathrm{mg} \mathrm{kg}^{-1}\right.$, i.p.) dosedependently reduced the oedema in both pre-emptive and curative treatments. In the Freund's adjuvant induced-arthritis model in rats, HLE as well as the positive controls, dexamethasone and methotrexate, showed significant anti-arthritic properties when applied to established adjuvant arthritis. HLE $\left(10-300 \mathrm{mg} \mathrm{kg}^{-1}\right.$, p.o.) significantly reduced oedema in the ipsilateral paw of rats but failed to prevent systemic arthritic spread. The DMARD methotrexate $\left(0.1-1 \mathrm{mg} \mathrm{kg}^{-1}\right.$, i.p. $)$ and dexamethasone (0.3-3 $\mathrm{mg} \mathrm{kg}^{-1}$, i.p.) reduced significantly the total polyarthritic oedema as well as the spread of the arthritis from the ipsilateral to the contralateral paws of the treated animals. The extract (0.03-1.00 mg ml$\left.{ }^{-1}\right)$ exhibited $\mathrm{Fe}^{3+}$ reducing activity, scavenged DPPH and prevented lipid peroxidation. These findings suggest that the extract exerts in vivo antiinflammatory activity after oral administration and also has antioxidant properties which may contribute to its activity.
\end{abstract}

Keywords: Carrageenan, chicks, DPPH, Freund's adjuvant-induced arthritis, lipid peroxidation, total phenol

\section{Introduction}

Inflammatory diseases continue to be one of the main health problems of the world's population. Although several agents are known to treat these types of disorders, prolonged use is undesirable due to the severe side effects. Consequently, there is a need to develop new anti-inflammatory agents with minimum side effects (Vane and Botting, 1995; Al-Turki et al., 2010). Medicinal plant drug discovery continues to provide new and important leads against various pharmacological targets including inflammation (Braddock, 2007; Shah et al., 2011). In Ghanaian traditional medicine, various parts of several plants are used either alone or in combination therapy in the treatment of various inflammatory conditions.

Hilleria latifolia (Lam.) H. Walt. (Family: Phytolaccaceae) is a perennial herb that is common on cultivated grounds and along forest paths in Ghana. It also occurs in other parts of tropical Africa as well as South America. It is commonly known as Avegboma, Boe or Kukluigbe by the Ewes and Anafranaku by the Akans. In Ghanaian traditional medicine, different parts of the plant have been used in a variety of diseases. The leaves are effective against otalgia (Mshana et al., 2000), rheumatism (Dokosi, 1998; Mshana et al., 2000) and boils (Dokosi, 1998). The flowers are used for asthma (Mshana et al., 2000). H. latifolia is also used in Cote d'Ivoire for feverish pains and violent headache whereas the leaves are used to treat some skin diseases in Congo (Dokosi, 1998). To date, there is little scientific evidence to support the traditional use of $H$. latifolia in the treatment of inflammatory-related diseases and the possible mechanisms involved.

The present study examined the effect of the ethanolic extract of the aerial parts of $H$. latifolia on acute and chronic inflammation. Since antioxidant activity may be one of the mechanisms of anti-inflammatory action of the plant extract, this was also investigated in various in vitro models. This study provides justification for the use of $H$. latifolia in Ghanaian traditional medicine for the treatment of inflammatory-related disorders.

\section{Materials and Methods Plant material}

The aerial parts of $H$. latifolia were collected from the campus of Kwame Nkrumah University of Science and Technology (KNUST), Kumasi near the Botanical Gardens $\left(06^{\circ} 41^{\prime} 12.89^{\prime \prime} \mathrm{N} ; 01^{\circ} 33^{\prime} 59.51^{\prime \prime} \mathrm{W}\right)$ during the month of July, 2007 and authenticated at the Department of Pharmacognosy, Faculty of Pharmacy and Pharmaceutical Sciences, College of Health Sciences, KNUST, Kumasi, Ghana. A voucher specimen (KNUST/HM1/09/L029) was kept at the herbarium of the Faculty.

\section{Preparation of extract}

The plant was room-dried for seven days and pulverised into fine powder. The powder was extracted by cold percolation with $70 \%(\mathrm{v} / \mathrm{v})$ ethanol and then concentrated into a green syrupy mass under reduced pressure at $60{ }^{\circ} \mathrm{C}$ using a 
rotary evaporator. It was further dried in a hot air oven at $50{ }^{\circ} \mathrm{C}$ for a week and kept in a refrigerator for use. The yield was $19.67 \%$. This crude extract is subsequently referred to as HLE or extract in this study.

\section{Animals}

Cockerels (Gallus gallus; strain Shaver 579, Akropong Farms, Kumasi, Ghana) were obtained one day post-hatch and housed in stainless steel cages $(34 \mathrm{~cm} \times 57 \mathrm{~cm} \times 40 \mathrm{~cm})$ at a population density of 12-13 chicks per cage. Food (Chick Mash, GAFCO, Tema, Ghana) and water were available ad libitum through 1-qt gravity-fed feeders and waterers. Overhead incandescent illumination was provided with room temperature at $29^{\circ} \mathrm{C}$. Chicks were tested at 7 days of age. SpragueDawley rats of both sexes (120-215 g) were purchased from Noguchi Memorial Institute for Medical Research, University of Ghana, Legon, Ghana and housed in the animal facility of the Department of Pharmacology, KNUST. The animals were housed in groups of six in stainless steel cages $(34 \mathrm{~cm} \times 47 \mathrm{~cm} \times 18 \mathrm{~cm})$ with soft wood shavings as bedding, fed with normal commercial pellet diet (GAFCO, Tema, Ghana), given water ad libitum. All procedures and techniques used in these studies were in accordance with accepted principles for laboratory animal use and care (EU directive of 1986: 86/609/EEC). All protocols used were approved by the Departmental Ethics Committee.

\section{Drugs and Chemicals}

The following drugs and chemicals were used: diclofenac sodium (KRKA, Slovenia); dexamethasone sodium phosphate (Pharm-Inter, Brussels, Belgium); methotrexate sodium (Dabur Pharma, New Delhi, India); carrageenan sodium salt, thiobarbituric acid (TBA), 2, 2-diphenyl-1-picrylhydrazyl (DPPH), trichloroacetic acid (TCA), Folin-Ciocalteau reagent (Sigma-Aldrich Inc., St. Louis, MO, USA); ascorbic acid, ammonium molybdate, disodium hydrogen phosphate $\left(\mathrm{Na}_{2} \mathrm{HPO}_{4}\right)$, sodium dihydrogen phosphate $\left(\mathrm{NaH}_{2} \mathrm{PO}_{4}\right)$, ferric chloride, linoleic acid, methanol, ethanol, $n$-propyl gallate, potassium ferricyanide, sodium bicarbonate, sodium carbonate, sulphuric acid, tannic acid (BDH, Poole, England).

\section{Phytochemistry}

The presence of saponins, alkaloids, flavonoids, steroids, terpenoids, glycosides and tannins were tested by methods described by Trease and Evans (1989).

\section{Carrageenan-induced Oedema in Chicks}

The anti-inflammatory activity of HLE was assessed using the carrageenan-induced foot oedema model in the chick (Roach and Sufka, 2003) as described earlier by Woode et al. (2009). Two sets of experiments were performed to assess the anti-inflammatory activity of HLE. The first was to study the effect of the drugs administered $1 \mathrm{~h}$ post carrageenan injection. The second examined the effects of the drugs given pre-emptively ( $30 \mathrm{~min}$ for i.p. route and $1 \mathrm{~h}$ for oral route) before the carrageenan challenge. Groups of chicks $(n=6)$ were treated with HLE suspended in $2 \%$ tragacanth $(10-300 \mathrm{mg}$ $\mathrm{kg}^{-1}$, p.o.). Dexamethasone (0.3-3.0 mg kg-1, i.p) and diclofenac (10-100 mg kg-1, i.p.) were used as standards. Drug vehicle $\left(2 \%\right.$ tragacanth, $10 \mathrm{ml} \mathrm{kg}^{-1}$, p.o.) served as a control.

\section{Freund's Adjuvant-Induced Arthritis (AIA) Induction of AIA}

Adjuvant arthritis was induced as previously described by Pearson (1956) with modifications (Abotsi et al., 2010). Briefly, right hind paw of rats were injected intraplantar with $0.1 \mathrm{ml}$ of Complete Freund's Adjuvant (CFA). The CFA was a $4 \mathrm{mg} \mathrm{ml}^{-1}$ suspension of heat killed Mycobacterium tuberculosis [strains C, DT and PN (mixed) obtained from the Ministry of Agriculture, Fisheries and Food, U.K] in paraffin oil. A non-arthritic control (IFA group) received only intraplantar injection of $0.1 \mathrm{ml}$ Incomplete Freund's Adjuvant (IFA) (sterile paraffin oil). Nine days after inoculation, the animals were selected and distributed into eleven groups $(n=6)$ according to the severity of arthritis, so that each group had similar disease severity at the beginning of the treatment. The vehicle-treated group (CFA group/arthritic control) received only normal saline daily; the others were given HLE $\left(10-300 \mathrm{mg} \mathrm{kg}^{-1} \mathrm{day}^{-1}\right.$, p.o.) or dexamethasone (0.3-3 mg kg $\mathrm{g}^{-1}$, i.p.; on alternate days) or methotrexate (0.1-1 mg kg${ }^{-1}$, i.p.; every 4 days) from day 9 to day 28 . The extract was suspended in $2 \%$ tragacanth mucilage whilst the reference drugs were dissolved in normal saline.

\section{Evaluation of the Severity of Arthritis}

Hind paw thickness were measured as previously described (Hoffmann et al., 1997) using digital callipers. The paw thicknesses were measured for both the ipsilateral and the contralateral hind limbs before intraplantar injection of CFA (day 0 ) and every other day up to the 28th day. The oedema component of inflammation was quantified by measuring the difference in paw thickness between day 0 and the various time points. The loss of body weight typical of this model of arthritis was also monitored every four days. On day 29 , the severity of arthritis was graded in a blinded manner by the same person according to the method previously described (Kinne et al., 1995; Abotsi et al., 2010). The hind paw thickness and arthritic index were used as the measurement parameters of inflammation and arthritis.

\section{Radiographic Assessment}

Radiographs of the hind limbs are important and were obtained from selected animals on day 29 in a manner 
similar to that described previously (Abotsi et al., 2010). Using the radiographs, the severity of bone and joint destruction was scored blindly by the same person for each hind limb, according to the method described by Hoffmann et al. (1997). The radiological score was termed the radiological index.

\section{Effects on Some Antioxidant Enzymes}

Plasma antioxidant enzymes — superoxide dismutase and catalase - which may contribute to the anti-inflammatory activity of HLE were assessed. Superoxide dismutase (SOD) enzyme activity was determined in plasma according to the method of Misra and Fridovich (1972) with modifications for a microassay. Briefly, $10 \mu 1$ of diluted plasma samples were added to a 96-well plate followed by $300 \mu \mathrm{l}$ of carbonate buffer $(0.05 \mathrm{M}, \mathrm{pH} 10.2,0.1 \mathrm{mM}$ EDTA). Ten microlitres of 9.6 $\mathrm{mM}$ epinephrine $(0.3 \mathrm{mM}$ final concentration in well) was then added to mixture in each well. The assay plate was then immediately inserted into a BioTek absorbance microplate reader (Model: ELx808, BioTek Instruments, Inc., Vermont, USA) and the change in absorbance at $490 \mathrm{~nm}$ was recorded for $4 \mathrm{~min}$. The enzyme activity was expressed as the amount of enzyme that inhibits the oxidation of adrenaline by $50 \%$ which is equal to 1 unit. Catalase (CAT) was measured by tracing the degradation of $\mathrm{H}_{2} \mathrm{O}_{2}$ spectrophotometrically, according to the method of Aebi (1974). The enzyme activity was expressed in units per millilitre $(\mathrm{U} / \mathrm{ml})$ using a micromolar extinction coefficient for $\mathrm{H}_{2} \mathrm{O}_{2}$ of $0.0436 \mathrm{~cm}^{2} \mu \mathrm{mole}^{-1}$. One unit is defined as that amount of enzyme causing the decomposition of one micromole of hydrogen peroxide per minute at $25^{\circ} \mathrm{C}$ and $\mathrm{pH}$ 7.0.

\section{In vitro Antioxidant Activity Total Phenol Assay}

Total soluble phenolics present in HLE was determined by a colorimetric method using the Folin-Ciocalteau reagent (Slinkard and Singleton, 1977). Various concentrations of HLE (0.1-3.0 $\left.\mathrm{mg} \mathrm{ml}^{-1}\right)$ were used with tannic acid (0.01$0.3 \mathrm{mg} \mathrm{ml}^{-1}$ ) as a reference standard. The total phenolics were expressed as milligrams per millilitre of tannic acid equivalents (TAEs).

\section{Antioxidant capacity by the Phosphomolybdate method}

The total antioxidant capacity assay was carried out according to the method described by Prieto et al. (1999). Various aqueous concentrations of HLE $\left(0.1-3 \mathrm{mg} \mathrm{m}^{-1}\right)$ were prepared, centrifuged and used for this test. Ascorbic acid $\left(0.01,0.03,0.1,0.3 \mathrm{mg} \mathrm{ml}^{-1}\right)$ was used as the standard and the total antioxidant capacity was expressed as milligrams per millilitre of ascorbic acid equivalents (AAE).

\section{Reducing power}

The antioxidant potential of the extract was determined using the $\mathrm{Fe}^{3+}$ reduction (reducing power test) described by Oyaizu (1986). Various concentrations of HLE $\left(0.03-1 \mathrm{mg} \mathrm{m}^{-1}\right)$ as well as the standard antioxidant $n$-propyl gallate $(0.001-0.03 \mathrm{mg}$ $\mathrm{ml}^{-1}$ ) were assessed. From the results, the concentration of the extract required to cause a $50 \%$ decrease in the absorbance was calculated (EC50).

\section{Scavenging of 2, 2-diphenyl-1-picrylhydrazyl (DPPH)}

The free radical scavenging activity was determined using method as described by Blois (1958). Methanolic solutions of HLE and standard antioxidant $n$-propyl gallate were prepared, centrifuged and the supernatant used for the experiment. Results were expressed as percentages of blank and the concentration of extracts required to cause a $50 \%$ decrease in the absorbance was calculated $\left(\mathrm{EC}_{50}\right)$.

\section{Linoleic acid autoxidation}

The inhibitory effect of HLE on lipid peroxidation was determined by the thiobarbituric acid method of the linoleic acid autoxidation assay as described previously by Inatani et al. (1983) but with slight modifications. Briefly, a mixture of 2 $\mathrm{ml}$ of HLE $\left(0.1,0.3,1,3 \mathrm{mg} \mathrm{ml}^{-1}\right)$ in $99.5 \%$ ethanol, $2.05 \mathrm{ml}$ of $2.51 \%(\mathrm{v} / \mathrm{v})$ linoleic acid in $99.5 \%$ ethanol, $4 \mathrm{ml}$ of phosphate buffer $(0.05 \mathrm{M}, \mathrm{pH} 7.0)$, and $1.95 \mathrm{ml}$ of water was placed in a vial with a screw cap and placed in an oven at $40{ }^{\circ} \mathrm{C}$ in the dark for 7 days. To $2 \mathrm{ml}$ of the mixture, which was prepared above, was added $2 \mathrm{ml}$ of $20 \%$ trichloroacetic acid aq. solution and $1 \mathrm{ml}$ of $0.67 \%$ thiobarbituric acid aq. solution. This mixture was placed in a boiling water bath for $10 \mathrm{~min}$ and, after cooling, was centrifuged at $650 \mathrm{~g}$ for $10 \mathrm{~min}$. The absorbance of the supernatant was measured at $532 \mathrm{~nm}$. Ethanol was used as blank throughout the experiment whilst $n$-propyl gallate $\left(0.003,0.01,0.03,0.1 \mathrm{mg} \mathrm{ml}^{-1}\right)$ was used as standard. Each test was carried out in duplicates. Percentage inhibition of linoleic acid autoxidation by the test drugs was assessed, comparing the absorbance of the drug test with that of the control (mixture without any test drug). Data was presented as percentage inhibition of linoleic acid autoxidation against concentration.

\section{Analysis of Data}

For the acute inflammation experiment, raw scores for right foot volumes were individually normalized as percentage of change from their values at time 0 then averaged for each treatment group. The time-course curves for foot volume were subjected to two-way (treatment $\times$ time) repeated measures analysis of variance with Bonferroni's post hoc test. 
Total foot volume for each treatment was calculated in arbitrary unit as the area under the curve (AUC) and to determine the percentage inhibition for each treatment, the following equation was used.

$$
\% \text { inhibition of oedema }=\left(\frac{A U C_{\text {control }}-A U C_{\text {treatment }}}{A U C_{\text {control }}}\right) \times 100
$$

Data from the arthritis experiment was treated the same as in the acute inflammation study. Raw scores for ipsilateral and contralateral paw thicknesses were individually normalized as percentage of change from their values at day 0 and then averaged for each treatment group. Data was presented as the effect of drugs on the time course and the total oedema response of adjuvant-induced arthritis for the 28 days period. The time-course curves for paw diameters were subjected to two-way (treatment $\times$ time) repeated measures analysis of variance with Bonferroni's post hoc test. Total paw thickness for each treatment was calculated in arbitrary unit as the AUC and to determine the percentage inhibition for each treatment.

Differences in AUCs were analysed by one-way ANOVA followed by Student-Newman-Keuls post hoc test. ED $50, \mathrm{EC}_{50}$ and $\mathrm{IC}_{50}$ (dose/concentration responsible for $50 \%$ of the maximal effect) values were determined by using an iterative computer least squares method, with the following nonlinear regression (three-parameter logistic) equation:

$$
Y=\frac{a+(b-a)}{\left(1+10^{\left(\operatorname{LogED}_{50}-X\right)}\right)}
$$

Where, $X$ is the logarithm of dose and $Y$ is the response. $Y$ starts at $a$ (the bottom) and goes to $b$ (the top) with a sigmoid shape.

The fitted midpoints $\left(\mathrm{ED}_{50} \mathrm{~s}\right)$ of the curves were compared statistically using $F$ test (Miller, 2003; Motulsky and Christopoulos, 2003). GraphPad Prism for Windows version 5 (GraphPad Software, San Diego, CA, USA) was used for all statistical analyses and $\mathrm{ED}_{50}$ determinations. $P<0.05$ was considered statistically significant.

\section{Results \\ Phytochemistry}

Preliminary phytochemical screening of HLE revealed the presence of saponins, tannins, glycosides, steroids, terpenoids as well as little amounts of flavonoids and alkaloids.

\section{Carrageenan-induced Oedema in Chicks}

Administration of carrageenan ( $10 \mu 1,2 \%$ suspension) induced moderate inflammation resulting in foot oedema in the 7-day old chicks peaking at 2-3 h as described by Roach and Sufka (2003)(Figure 1). Figures 1 (a, c, e) and 2 (a, c, e) show the time course curves for effects of HLE, diclofenac and dexamethasone on carrageenan-induced oedema. Two-way ANOVA (treatment $\times$ time) revealed a significant effect of drug treatment for HLE (pre-emptive: $F_{3}, 120=28.59, P<0.0001$; curative: $F_{4}, 25=2.87, P=0.044$ ), diclofenac (pre-emptive: $F_{3},{ }_{120}=27.60, P<0.0001$; curative: $F_{3},{ }_{20}=4.96, P=0.0098$ ) and dexamethasone (pre-emptive: $F_{3},{ }_{120}=34.14, P<0.0001$; curative: $F_{3},{ }_{20}=3.74, P<0.028$ ). Total oedema produced by each treatment is expressed in arbitrary units as AUC of the time-course curves.

HLE (30-300 mg kg ${ }^{-1}$, p.o.) significantly reduced foot oedema with maximal inhibition of $38.11 \pm 5.55 \%$ and $30.91 \pm 4.66 \%$ for pre-emptive (Figure $1 \mathrm{~b}$ ) and curative (Figure $2 \mathrm{~b}$ ) treatments respectively. Similarly, the NSAID diclofenac (10-100 mg kg${ }^{-1}$, i.p.) dose dependently reduced the oedema by $59.33 \pm 10.82 \%$ and $42.87 \pm 7.46 \%$ respectively for preemptive (Figure 1d) and curative treatments (Figure 2d). Dexamethasone (0.3-3 mg kg-1 i.p.), a steroidal anti-inflammatory agent inhibited the oedema with maximal effect of $42.77 \pm 7.64 \%$ (pre-emptive; Figure 1f) and $36.60 \pm 6.76 \%$ (curative; Figure 2f). Dose-response curves for the inhibition of foot oedema are shown in Figure 4. HLE displayed a U-shaped dose response relationship with approximate $\mathrm{ED}_{50}$ values: 59.70 and $151.01 \mathrm{mg} \mathrm{kg}^{-1}$ (pre-emptive treatment); 72.95 and $213.80 \mathrm{mg}$ $\mathrm{kg}^{-1}$ (curative treatment). By comparing the $\mathrm{ED}_{50}$ values from the curves, HLE was significantly less potent than diclofenac ( $\mathrm{ED}_{50}$ pre-emptive: $11.58 \pm 17.83 \mathrm{mg} \mathrm{kg}^{-1}$, curative: $\left.25.65 \pm 32.48 \mathrm{mg} \mathrm{kg}^{-1}\right)$ and dexamethasone $\left(\mathrm{ED}_{50}\right.$ pre-emptive: $0.77 \pm 0.85$ mg kg${ }^{-1}$, curative: $2.93 \pm 1.02 \mathrm{mg} \mathrm{kg}^{-1}$ ).

\section{Adjuvant - Induced Arthritis}

Intraplantar injection of CFA into the right foot pad of rats induced an inflammatory response characterized by paw swelling in both the ipsilateral and the contralateral paw. The response on the injected paw was biphasic. It consisted of an acute phase (days 0-10 post CFA inoculation) characterized by unilateral inflammatory oedema of the ipsilateral paw peaking around days 4-6 and a subsequent polyarthritic/chronic phase (10-28 post CFA inoculation) characterised by inflammatory oedema of the contralateral paw. Throughout the 28-day experiment, there was no significant change in the paw volume of the non-inflamed control groups injected with IFA. 

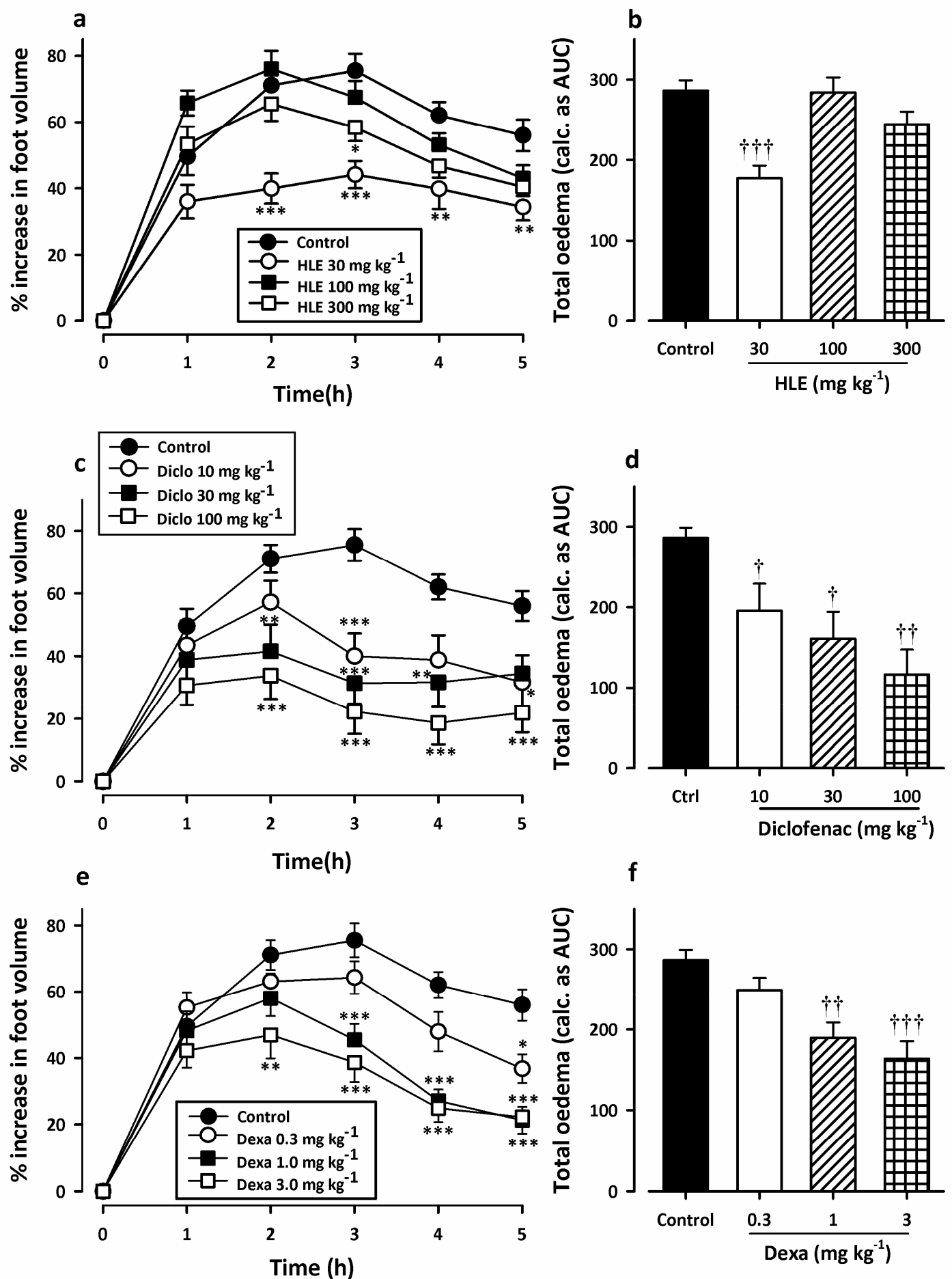

Figure 1: Effect of HLE (30-300 mg kg-1; p.o.), diclofenac (10-100 mg kg-1, i.p.) and dexamethasone (0.3-3 mg kg $\mathrm{mg}^{-1}$, i.p.) on time-course curves (a, c and e respectively) and the total oedema response (b, $\mathrm{d}$ and $\mathrm{f}$ respectively) in the preemptive protocol of carrageenan-induced foot oedema in chicks. Values are means \pm S.E.M. $(\mathrm{n}=6) .{ }^{*} P<0.05$; ${ }^{* *} P<0.01 ; * * * P<0.001$ compared to vehicle-treated group (Two-way ANOVA followed by Bonferroni's post hoc test). ${ }^{\dagger} P<0.05 ;{ }^{\dagger \dagger} P<0.01 ;{ }^{\dagger \dagger} P<0.001$ compared to vehicle-treated group (One-way ANOVA followed by NewmanKeuls post hoc test). 

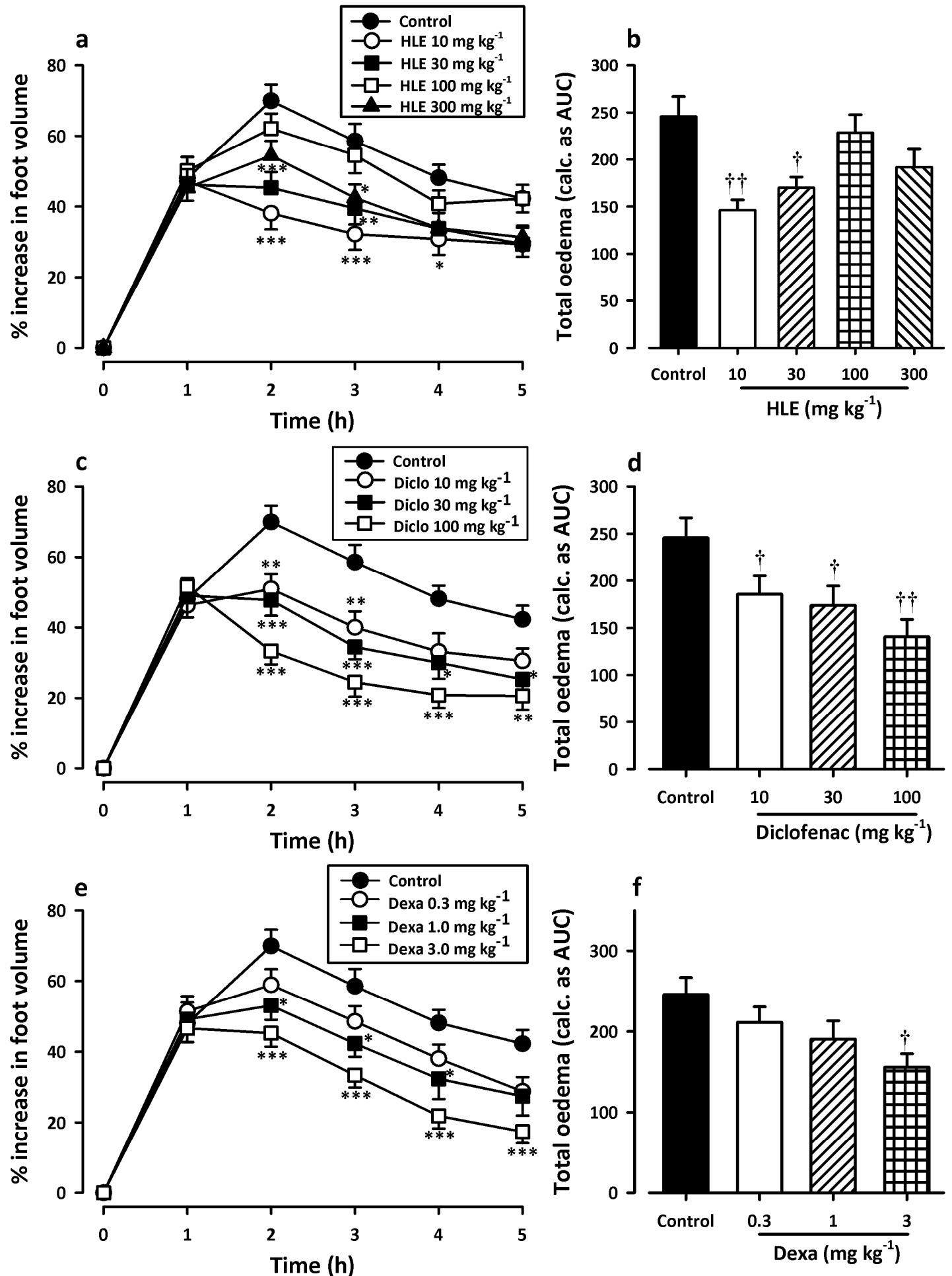

Figure 2: Effect of HLE (10-300 mg kg-1; p.o.), diclofenac (10-100 $\mathrm{mg} \mathrm{kg}^{-1}$, i.p.) and dexamethasone $\left(0.3-3 \mathrm{mg} \mathrm{kg}^{-1}\right.$, i.p.) on time-course curves(a, $\mathbf{c}$ and $\mathbf{e}$ respectively) and the total oedema response ( $\mathbf{b}, \mathbf{d}$ and $\mathbf{f}$ respectively) in the curative protocol of carrageenan-induced foot oedema in chicks. Values are means \pm S.E.M. $(\mathrm{n}=6) .{ }^{*} P<0.05 ; * * P<0.01$; $* * * P<0.001$ compared to vehicle-treated group (Two-way ANOVA followed by Bonferroni's post hoc test). ${ }^{\dagger} P<0.05 ;{ }^{\dagger \dagger} P<0.01 ;{ }^{\dagger \dagger} P<0.001$ compared to vehicle-treated group (One-way ANOVA followed by Newman-Keuls post hoc test). 
HLE, dexamethasone and methotrexate significantly suppressed the time-course of ipslateral and contralateral paw oedema in rats. Two-way ANOVA (treatment $\times$ time) revealed a significant effect of drug treatments on the paw oedema (HLE: $F_{5,30}=78.44, P<0.0001$; dexamethasone: $F_{4,25}=144.88, P<0.0001$ and methotrexate: $F_{4,25}=80.05, P<0.0001$; Figure $\left.3 \mathrm{a}, \mathrm{c}, \mathrm{e}\right)$.

HLE (10-300 mg kg$\left.{ }^{-1}, p . o\right)$ significantly reduced the total ipslateral paw oedema response over the 19 days of treatment with a maximal inhibition of $32.64 \pm 2.74 \%$ (Figure $3 b$ ). Similarly, the DMARD methotrexate $\left(0.1-1 \mathrm{mg} \mathrm{kg}^{-1}\right.$, i.p.) and dexamethasone $\left(0.3-3 \mathrm{mg} \mathrm{kg}^{-1}\right.$, i.p ) profoundly reduced the total ipslateral paw oedema by $57.30 \pm 4.96 \%$ (Figure $3 \mathrm{f}$ ) and $64.51 \pm 2.30 \%$ (Figure $3 \mathrm{~d}$ ) respectively. HLE $\left(10-300 \mathrm{mg} \mathrm{kg}^{-1}\right)$ could not significantly reduce $\left(F_{4,25}=0.74, P=0.57\right)$ the extent of spread of oedema from the ipsilateral to the contralateral paw (Figure 3a, b). However, dexamethasone $\left(F_{4,25}=9.23\right.$, $P=0.0001)$ and methotrexate $\left(F_{4,25}=7.04, P=0.0006\right)$ significantly prevented the spread of the arthritis from the ipsilateral to the contralateral paws of the treated animals (Figure 3c, d, e, f). Dose-response curves for the inhibition of paw oedema are shown in Figure 4c. HLE displayed a bell-shaped dose response relationship with approximate ED $_{50}$ values: 19.91 and 47.64 $\mathrm{mg} \mathrm{kg}^{-1}$. HLE was the least potent compared to methotrexate and dexamethasone. Dexamethasone was the most potent.

The body weight changes of rats in each treatment group over the 28 days period is shown in Table 2 . Rats in the IFA control group gained the most weight $(43.75 \pm 8.31 \%)$. HLE $10 \mathrm{mg} \mathrm{kg}^{-1}$ showed weight gain comparable to the CFA group. However, there was a general dose-dependent reduction in weight gain in HLE treated group. Dexamethasone (0.3-3 $\left.\mathrm{mg} \mathrm{kg}^{-1}\right)$ caused significant $\left(F_{3,20}=12.70, P<0.0001\right)$ weight loss compared to the CFA group. Except for the dose of $0.3 \mathrm{mg}$ $\mathrm{kg}^{-1}$, rats in the methotrexate treated group generally gained weight comparable to that of the CFA group.

The results from the assay of superoxide dismutase and catalase are shown in Table 3. There was a decrease in SOD and CAT activity levels in the CFA-treated group compared to the IFA-treated group. Except for HLE at doses 10 and 300 $\mathrm{mg} \mathrm{kg}^{-1}$, all drug treatments did not significantly affect plasma SOD levels compared to the CFA group. In the case of catalase, all the drug treatments failed to reverse $\left(F_{11,24}=1.32 ; P=0.276\right)$ the fall in the enzyme levels induced by the adjuvant arthritis.

Table 1: Arthritic and radiological indices of rats in the adjuvant-induced arthritis.

\begin{tabular}{lll}
\multicolumn{1}{c}{ Table 1: Arthritic and radiological indices of rats in the adjuvant-induced arthritis. } & Radiological Index \\
\hline Groups & Arthritic Index & \\
\hline IFA & $0^{* * *}$ & $0^{* * *}$ \\
CFA & $6.67 \pm 0.42$ & $3.33 \pm 0.21$
\end{tabular}

H. latifolia extract

$\begin{array}{lll}10 \mathrm{mg} \mathrm{kg}^{-1} & 2.67 \pm 0.33 * * * & 1.50 \pm 0.22 * * * \\ 30 \mathrm{mg} \mathrm{kg}^{-1} & 6.18 \pm 0.65 & 3.00 \pm 0.26 \\ 100 \mathrm{mg} \mathrm{kg}^{-1} & 4.50 \pm 1.03 * & 2.50 \pm 0.22 * \\ 300 \mathrm{mg} \mathrm{kg}^{-1} & 4.00 \pm 0.93 * * & 1.83 \pm 0.31 * * *\end{array}$

Dexamethasone

$\begin{array}{lll}0.3 \mathrm{mg} \mathrm{kg}^{-1} & 1.83 \pm 0.67^{* * *} & 0.17 \pm 0.17^{* * *} \\ 1 \mathrm{mg} \mathrm{kg}^{-1} & 1.33 \pm 0.21^{* * *} & 0^{* * *} \\ 3 \mathrm{mg} \mathrm{kg}^{-1} & 0.83 \pm 0.66^{* * *} & 0 * * *\end{array}$

Methotrexate

\begin{tabular}{lll}
$0.1 \mathrm{mg} \mathrm{kg}^{-1}$ & $2.40 \pm 0.51 * * *$ & $0.33 \pm 0.21 * * *$ \\
$0.3 \mathrm{mg} \mathrm{kg}^{-1}$ & $1.67 \pm 0.33^{* * *}$ & $0.20 \pm 0.20^{* * *}$ \\
$1 \mathrm{mg} \mathrm{kg}-1$ & $1.50 \pm 0.22 * * *$ & $0 * * *$ \\
\hline$<0.01 ; * * * P<0.001$ compared to CFA group (One-way ANOVA followed by Newman-Keuls post hoc test).
\end{tabular}

${ }^{*} P<0.05 ; * * P<0.01 ; * * * P<0.001$ compared to CFA group (One-way ANOVA followed by Newman-Keuls post hoc test).

From the arthritic indices (Table 1), HLE (10-300 mg kg$\left.{ }^{-1}\right)$, dexamethasone (0.3-3 mg kg$\left.{ }^{-1}\right)$ and methotrexate $(0.1$ $\left.1 \mathrm{mg} \mathrm{kg}^{-1}\right)$ showed significant $\left(F_{11,59}=15.58, P<0.0001\right)$ dose-dependent clinical improvement in arthritis. HLE reduced the arthritic index by a maximum of $60.00 \%$ whilst dexamethasone and methotrexate similarly inhibited by $87.50 \%$ and 77.50 $\%$ respectively. The CFA group developed the severest arthritis showing immense erythema and swelling in both the ipsilateral and contralateral paws. The IFA groups showed no sign of erythema or swelling. As regards the effectiveness of the doses of HLE used, $30 \mathrm{mg} \mathrm{kg}^{-1}$ was the least effective (Table 1).

From radiographic score of the hind limbs (Table 1), the CFA group demonstrated the most severe bone destruction displaying reduced bone density and focal areas of excessive bone resorption. The bones were intact in the IFA/non-arthritic control which recorded the lowest radiological index. HLE at doses 10 and $300 \mathrm{mg} \mathrm{kg}^{-1}$ suppressed the pathological changes 
in bone with maximal inhibition of radiological index of $54.95 \%$, compared with that of the CFA group. Similarly, dexamethasone $\left(0.3-3 \mathrm{mg} \mathrm{kg}{ }^{-1}\right)$ and methotrexate $\left(0.1-1 \mathrm{mg} \mathrm{kg}^{-1}\right)$ almost totally prevented bone destruction in AIA radiographically (Table 1); both reducing the radiological index by maxima of $100 \%$.
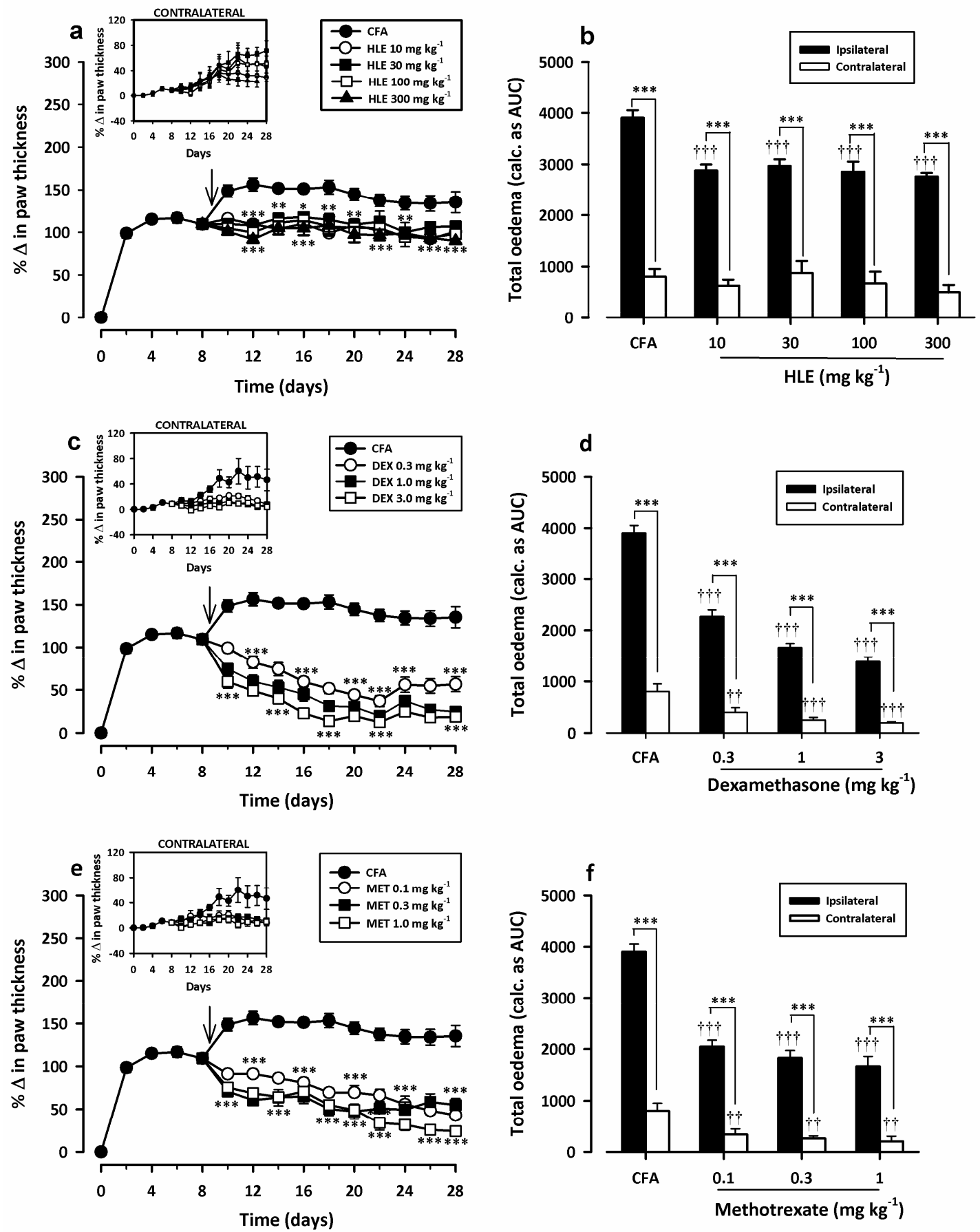

Figure 3: Effect of HLE (10 - $300 \mathrm{mg} \mathrm{kg}{ }^{-1}$; p.o. $)$, dexamethasone $\left(0.3-3 \mathrm{mg} \mathrm{kg}^{-1}\right.$; i.p. $)$ and methotrexate $\left(0.1-1 \mathrm{mg} \mathrm{kg}^{-1}\right.$; i.p.) on time course curve ( $\mathrm{a}, \mathrm{c}$ and e respectively) and the total oedema response ( $\mathrm{b}, \mathrm{d}$ and $\mathrm{f}$ respectively) in adjuvant-induced arthritis in rats. The total oedema was calculated as AUCs over the $19 \mathrm{~d}$ period of drug treatment. Values are means \pm S.E.M. $(\mathrm{n}=5)$. ${ }^{*} P<0.05 ;{ }^{*} P<0.01 ; * * * P<0.001$ compared to vehicle-treated group (Two-way ANOVA followed by Bonferroni's post hoc test). ${ }^{\dagger} P<0.05$; ${ }^{\dagger \dagger} P<0.01 ;{ }^{\dagger \dagger} P<0.001$ compared to vehicle-treated group (One-way ANOVA followed by Newman-Keuls post hoc test). 

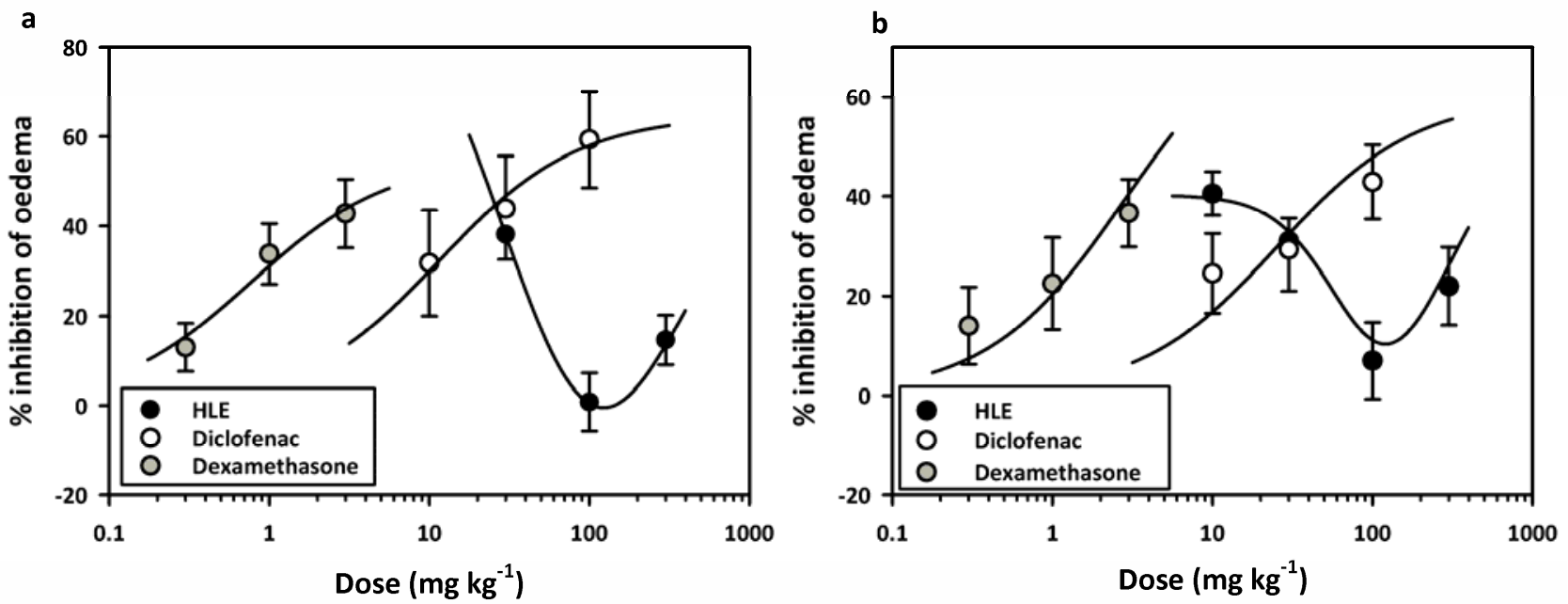

c



Figure 4: Dose response curves for HLE, diclofenac and dexamethasone in the pre-emptive (a) and curative (b) protocols of carrageenan-induced foot oedema in the chick and in Freund's adjuvant-induced arthritis (c) as well as for methotrexate in Freund's adjuvant-induced arthritis (c). Each point represents the mean $\pm \operatorname{SEM}(n=5-6)$.

\section{Total Phenol Content}

The total phenol content determination showed a concentration-dependent increase $\left(F_{3,6}=427.9, P<0.0001\right)$ in the total phenolics in HLE when expressed in tannic acid equivalents. The total phenol content was estimated to be $29.40 \pm 1.09$ $\mathrm{mg}$ tannic acid equivalent/g of HLE.

\section{Total Antioxidant Capacity}

HLE $\left(0.1-3 \mathrm{mg} \mathrm{ml}^{-1}\right)$ showed a concentration-dependent increase $\left(F_{3,8}=44.86, P<0.0001\right)$ in total antioxidant capacity when expressed as ascorbic acid equivalents. The total antioxidant capacity of the HLE was estimated to be $55.16 \pm 13.60 \mathrm{mg}$ ascorbic acid equivalent/g of HLE.

\section{Reducing Power}

HLE (0.03-1 mg ml$\left.{ }^{-1}\right)$ and $n$-propyl gallate $\left(0.001-0.03 \mathrm{mg} \mathrm{ml}^{-1}\right)$ exerted a concentration-dependent $\mathrm{Fe}^{3+}$ reducing activity with $\mathrm{EC}_{50}$ values (in $\mathrm{mg} \mathrm{ml}^{-1}$ ) of $2.071 \pm 0.782$ and $0.1071 \pm 0.049$ respectively (Figure 5). The $n$-propyl gallate was however more potent, exhibiting a 19 -fold reducing power compared to the extract $\left(F_{1,20}=7.76, P=0.0114\right)$.

\section{Scavenging of 2, 2-diphenyl-1-picrylhydrazyl (DPPH)}

The DPPH assay determines the ability of an agent to scavenge free radicals. HLE $\left(0.1-1 \mathrm{mg} \mathrm{ml}^{-1}\right)$ showed a concentration-dependent scavenging activity in a similar manner to $n$-propyl gallate (Figure 5). The $\mathrm{EC}_{50}$ values (in $\mathrm{mg} \mathrm{ml}^{-1}$ ) of $0.2269 \pm 0.037$ and $0.00323 \pm 0.001$ for HLE and $n$-propyl gallate respectively, suggests that HLE has lesser ability to scavenge free radicals compared to $n$-propyl gallate $\left(F_{1,14}=114.7, P<0.0001\right)$. 
Table 2: Body weights changes in adjuvant-induced arthritis in rats

Body weight changes (\%)

\begin{tabular}{|c|c|c|c|c|c|}
\hline Treatment & Day 0 & Day 8 & Day 16 & Day 24 & Day 28 \\
\hline IFA & 0 & $17.97 \pm 3.44 * * *$ & $37.92 \pm 7.45^{* * *}$ & $40.60 \pm 8.49^{* * *}$ & $43.75 \pm 8.31 * * *$ \\
\hline CFA & 0 & $-0.12 \pm 1.62$ & $5.87 \pm 2.60$ & $11.15 \pm 2.22$ & $14.35 \pm 1.76$ \\
\hline \multicolumn{6}{|l|}{ HLE } \\
\hline $10 \mathrm{mg} \mathrm{kg}^{-1}$ & 0 & $1.75 \pm 1.56$ & $8.20 \pm 1.68$ & $14.52 \pm 2.93$ & $17.37 \pm 4.39$ \\
\hline $30 \mathrm{mg} \mathrm{kg}^{-1}$ & 0 & $1.03 \pm 1.22$ & $1.15 \pm 1.38$ & $4.50 \pm 2.37$ & $5.10 \pm 2.70$ \\
\hline $100 \mathrm{mg} \mathrm{kg}^{-1}$ & 0 & $-0.68 \pm 3.43$ & $-3.27 \pm 4.18$ & $1.58 \pm 6.49$ & $0.73 \pm 6.68$ \\
\hline $300 \mathrm{mg} \mathrm{kg}^{-1}$ & 0 & $-0.50 \pm 1.94$ & $-1.82 \pm 1.89$ & $0.33 \pm 0.93$ & $-2.87 \pm 1.68^{* *}$ \\
\hline \multicolumn{6}{|l|}{ DEX } \\
\hline $0.3 \mathrm{mg} \mathrm{kg}^{-1}$ & 0 & $-1.25 \pm 2.06$ & $-6.70 \pm 2.22 * *$ & $-6.27 \pm 2.33 * * *$ & $-5.38 \pm 1.97 * * *$ \\
\hline $1.0 \mathrm{mg} \mathrm{kg}^{-1}$ & 0 & $0.13 \pm 0.75$ & $-5.95 \pm 2.18^{* * *}$ & $-6.58 \pm 2.19 * * *$ & $-6.08 \pm 2.42 * * *$ \\
\hline $3.0 \mathrm{mg} \mathrm{kg}^{-1}$ & 0 & $-1.87 \pm 2.15$ & $-9.13 \pm 1.62 * *$ & $-11.85 \pm 1.25^{* * *}$ & $-13.47 \pm 1.60 * * *$ \\
\hline \multicolumn{6}{|l|}{ MET } \\
\hline $0.1 \mathrm{mg} \mathrm{kg}^{-1}$ & 0 & $3.55 \pm 2.80$ & $6.45 \pm 3.82$ & $8.30 \pm 3.69$ & $9.03 \pm 3.84$ \\
\hline $0.3 \mathrm{mg} \mathrm{kg}^{-1}$ & 0 & $-10.37 \pm 9.33$ & $-9.19 \pm 4.72$ & $-0.31 \pm 3.41$ & $0.95 \pm 3.74$ \\
\hline $1.0 \mathrm{mg} \mathrm{kg}^{-1}$ & 0 & $1.68 \pm 0.93$ & $8.78 \pm 2.84$ & $12.12 \pm 3.54$ & $13.73 \pm 2.86$ \\
\hline
\end{tabular}

Values are mean $\pm \operatorname{SEM}(\mathrm{n}=5) . * * P<0.01 ; * * * P<0.001$ compared to CFA group (Two-way ANOVA followed byBonferroni's post hoc test). DEX: dexamethasone. MET: Methotrexate

\section{Linoleic Acid Autoxidation}

The result of the linoleic acid autoxidation determination (Figure 5) showed a concentration-dependent inhibitory activity by both HLE and the standard, $n$-propyl gallate with $\mathrm{IC}_{50}$ values (in $\mathrm{mg} \mathrm{ml}^{-1}$ ) of $0.1122 \pm 0.010$ and $0.03657 \pm 0.007$ respectively. $N$-propyl gallate was more potent when compared to FEE $\left(F_{1,14}=27.29, P=0.0001\right)$. 
a

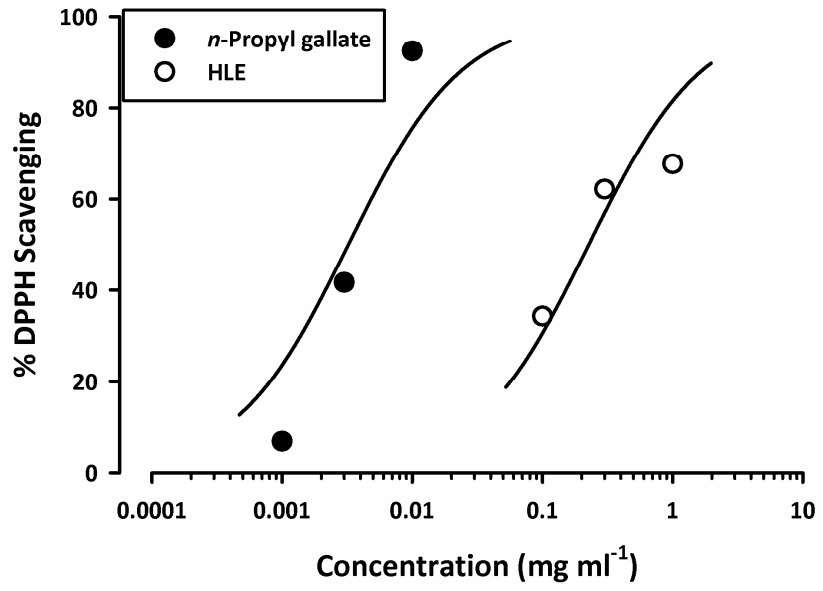

b



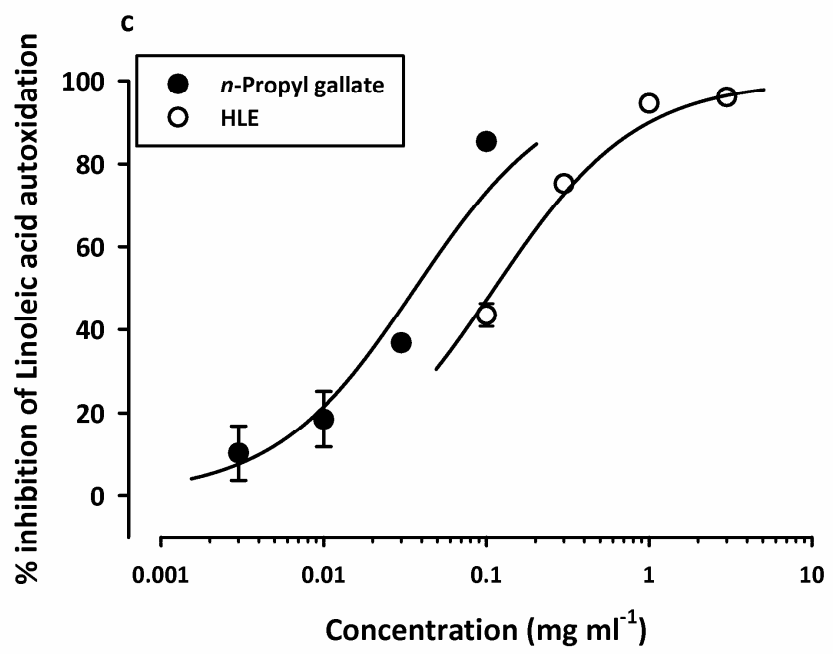

Figure 5: Free radical scavenging ability of $\operatorname{HLE}\left(0.1-1 \mathrm{mg} \mathrm{ml}^{-1}\right)$ compared to $n$-propyl gallate $\left(0.001-0.01 \mathrm{mg} \mathrm{ml}^{-1}\right)$ in the DPPH radical assay(a), reducing power of HLE $\left(0.03-1 \mathrm{mg} \mathrm{ml}^{-1}\right)$ compared to $n$-propyl gallate $\left(0.001-0.03 \mathrm{mg} \mathrm{ml}^{-}\right.$ $\left.{ }^{1}\right)(\mathrm{b})$, and Percentage inhibition of lipid peroxidation (linoleic acid autoxidation) by HLE $\left(0.1-3 \mathrm{mg} \mathrm{ml}^{-1}\right)$ compared to $n$-propyl gallate $\left(0.003-0.1 \mathrm{mg} \mathrm{ml}^{-1}\right)(\mathrm{c})$. Values are means \pm S.E.M.

\section{Discussion}

The present study established the anti-inflammatory activity of the aerial parts of $H$. latifolia in the acute and chronic inflammatory animal models used. It also evaluated the in vitro antioxidant properties of HLE, since it may be one of the mechanisms of its anti-inflammatory action. HLE exhibited antioxidant activity in all the five assays models used: total phenol assay, reducing power test, total antioxidant capacity, DPPH scavenging activity and lipid peroxidation assay.

Carrageenan-induced oedema test (Winter et al., 1962) is a classical model of acute inflammation that has been extensively used to screen new anti-inflammatory drugs (Di Rosa and Willoughby, 1971). In this study chicks were used instead of the commonly used rodents. Carrageenan-induced oedema has been validated in chicks (Roach and Sufka, 2003), and is much more economical than rodent models. Furthermore, chicks are easier to handle. The inflammatory response induced by carrageenan is characterized by a biphasic response (Vinegar et al., 1969) with marked oedema formation resulting from the rapid production of several inflammatory mediators such as histamine, serotonin and bradykinin (firstphase), which is subsequently sustained by the release of prostaglandins and nitric oxide (second-phase) with peak at $3 \mathrm{~h}$, produced by inducible isoforms of COX (COX-2) and nitric oxide synthase (iNOS), respectively (Seibert et al., 1994; Thomazzi et al., 2010). The second (late) phase is sensitive to most clinically effective anti-inflammatory drugs (Vinegar et al., 1969; Di Rosa et al., 1971). HLE clearly suppressed inflammation induced by carrageenan in both pre-emptive and curative protocols of the anti-inflammatory activity assessment. The finding justifies the use of the extract traditionally in the treatment of inflammatory conditions. Although the actual mechanism of action of HLE in inflammation is unknown, the fact that it inhibited both early and late phases of oedema suggests that it could be acting through the inhibition of the release 
and/or action of those inflammatory mediators involved in carrageenan-induced oedema which include cytoplasmic enzymes, histamine, serotonin, bradykinin, prostaglandins and other cyclooxygenase products. The exact mechanism, however, needs to be established.

Table 3: Effect of various treatments on the plasma levels of antioxidant enzymes SOD and CAT in adjuvant-induced arthritis in rats.

Treatment

IFA

CFA

$11.10 \pm 0.98$

HLE

$\begin{array}{ccc}10 \mathrm{mg} \mathrm{kg}^{-1} & 28.40 \pm 1.18^{*} & 77.42 \pm 2.71 \\ 30 \mathrm{mg} \mathrm{kg}^{-1} & 7.66 \pm 1.73 & 80.46 \pm 19.12 \\ 100 \mathrm{mg} \mathrm{kg}^{-1} & 11.73 \pm 1.34 & 86.29 \pm 22.38 \\ 300 \mathrm{mg} \mathrm{kg}^{-1} & 16.02 \pm 6.04 & 66.22 \pm 21.10\end{array}$

Dexamethasone

$\begin{array}{llc}0.3 \mathrm{mg} \mathrm{kg}^{-1} & 9.54 \pm 0.80 & 84.79 \pm 18.69 \\ 1.0 \mathrm{mg} \mathrm{kg}^{-1} & 8.17 \pm 1.78 & 97.44 \pm 33.00 \\ 3.0 \mathrm{mg} \mathrm{kg}^{-1} & 8.75 \pm 1.18 & 96.47 \pm 9.57\end{array}$

Methotrexate
$0.1 \mathrm{mg} \mathrm{kg}^{-1}$
$8.61 \pm 0.30$
$108.61 \pm 8.59$
$0.3 \mathrm{mg} \mathrm{kg}^{-1}$
$11.32 \pm 0.80$
$102.3 \pm 16.16$
$1.0 \mathrm{mg} \mathrm{kg}^{-1}$
$7.28 \pm 0.88$
$51.54 \pm 13.01$

Values are mean $\pm \operatorname{SEM}(\mathrm{n}=3) .{ }^{*} P<0.05$ compared to CFA group (One-way ANOVA followed by Newman-Keuls post hoc test). SOD: Superoxide dismutase; CAT: Catalase.

Adjuvant-induced arthritis (AIA) is one of the most widely used animal models to study the effect of antirheumatic agents and represents a systemic inflammatory disease, with bone and cartilage changes similar to those observed in rheumatoid arthritis, but with an accelerated time span (Osterman et al., 1994). The common pathological features of adjuvant arthritis in rat and rheumatoid arthritis in humans are joint swelling associated with cellular and pannus invasion of the joint space, release of lysosomal constituents into the joint space, and bone resorption (Osterman et al., 1994). The induction of adjuvant arthritis is thought to be due to bacterial peptidoglycan and muramyl dipeptide and occurs through cell mediated-autoimmunity by structural mimicry between mycobacteria and cartilage proteoglycans in rats (van Eden et al., 1985; Vijayalakshmi et al., 1997). In this study, oral administration of HLE caused clinical improvement of arthritis and a significant reduction in inflammation shown as decrease in paw thickness. The action of HLE on arthritis seems to be largely anti-inflammatory (i.e. reduction in oedema, erythema, pain, etc, as seen in the acute model) rather than an immunologic effect on the course of the disease. This argument is supported by the fact that HLE did not significantly prevent the systemic spread of the adjuvant arthritis - a process that is largely immunologic (Donaldson et al., 1995). Nevertheless, further studies are needed to establish these assertions.

Radiographs are necessary to determine true remission of disease and for accurate evaluation of disease status

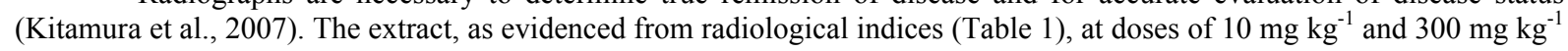
protected against bone loss due to reduced bone formation and increased resorption which are the causes of bone loss in 
adjuvant-induced arthritis in rats (Aota et al., 1996; Findlay and Haynes, 2005). It is doubtful if this effect is mediated by an immunologic protection of the bones. It is most likely due to protection offered to the bone as a result of the antiinflammatory effect of HLE, which was most seen at the two doses (i.e. $10 \mathrm{mg} \mathrm{kg}^{-1}$ and $300 \mathrm{mg} \mathrm{kg}^{-1}$ ). Further studies on the effect of HLE on the bone will be necessary to establish exact mechanisms.

Changes in weight reflect arthritic disease progression and general health status, while exaggerated weight loss above that observed in the arthritic control group may be indicative of toxicity (Schopf et al., 2006). Generally, the extract could not protect against arthritic-induced weight loss. While the least dose of the extract $\left(10 \mathrm{mg} \mathrm{kg}^{-1}\right)$ permitted slight weight gain beyond the arthritic control (CFA) group, higher doses $\left(30-300 \mathrm{mg} \mathrm{kg}^{-1}\right)$ resulted in weight loss. This could be attributed to the fact that aside $10 \mathrm{mg} \mathrm{kg}^{-1}$ of HLE, the higher doses could not produce much clinical improvement in arthritis to allow significant weight gain. It is also possible that weight loses are due to HLE toxicity at high doses. Dexamethasone and methotrexate, which are well known to cause weight loss (Orzechowski et al., 2000; Lucas et al., 2003; Kolli et al., 2007), also acted similarly to HLE and were unable to offer protection against arthritis-induced weight loss.

HLE exhibited a non-monotonic dose-response pattern in both carrageenan-induced oedema test and the adjuvantinduced arthritis (Figure 4). The exact biochemical mechanism underlying this pharmacological inversion is not yet clear, and remains to be established. The anti-inflammatory action of HLE can be attributed to one of its chemical constituents. Indeed, HLE has been shown by phytochemical analysis to contain alkaloids, flavonoids, tannins, saponins, phytosterols and terpenoids and one of them may be responsible for the anti-inflammatory effect especially as a lot of these secondary plant metabolites identified have been shown to exhibit anti-inflammatory properties (Whitehouse et al., 1994; Guardia et al., 2001; Barbosa-Filho et al., 2006).

Activated neutrophils and macrophages are implicated in the release of free radicals and reactive oxygen species (ROS) in inflammation (Conner and Grisham, 1996). Since free radicals and ROS are important mediators that provoke or sustain inflammatory processes, their neutralization by antioxidants and radical scavengers can attenuate inflammation (Winrow et al., 1993; Conforti et al., 2008). Indeed, several anti-inflammatory agents have been shown to have antioxidant and/or radical scavenging mechanisms as part of their activity (Geronikaki and Gavalas, 2006). Consequently, one of the possible mechanisms by which HLE exerts anti-inflammatory activity is through the suppression of the effect of free radicals and ROS during inflammation. This can be achieved through the direct action of the extract as an antioxidant, or indirectly by boosting the levels of in vivo antioxidant enzymes including superoxide dismutase (SOD) and catalase (CAT). The impact of HLE on antioxidant enzymes SOD and CAT was investigated during the adjuvant arthritis experiment while the direct effect of HLE as an antioxidant was assessed with in vitro models.

Evidence suggests oxidative stress is elevated in arthritis (Bae et al., 2003; Mahajan and Tandon, 2004). This initially triggers feedback increases in activity of antioxidant enzymes but is usually overwhelmed, resulting ultimately in decreased activity of antioxidant enzymes including SOD and CAT (Vijayalakshmi et al., 1997; Kumar et al., 2002; Jung et al., 2005; Narendhirakannan et al., 2005; He et al., 2006). This was observed in this study-the arthritic control (CFA) group showed significant decrease in the antioxidant enzymes SOD and CAT compared to the non-arthritic control (IFA) group. HLE at doses $10 \mathrm{mg} \mathrm{kg}^{-1}$ and $300 \mathrm{mg} \mathrm{kg}^{-1}$ caused an increase in SOD. This could be attributed to transcriptional activation of the enzyme or amelioration of oxidative stress by HLE at these doses. HLE, however, did not affect the decreased levels of catalase induced by the arthritis. Dexamethasone and methotrexate did not also significantly reverse the arthritis-induced reduction in the levels of SOD and catalase.

From the powerful activity shown by HLE in vitro with reference to free radical scavenging, reducing capacity and inhibition of lipid peroxidation, it is clear that HLE is an antioxidant. The mechanism of antioxidant activity of HLE can be stipulated from above findings as the reduction of free radicals as well as scavenging of reactive oxygen species and other free radicals. The observed in vitro activities suggest that HLE could exert protective effects also in vivo against oxidative and free radical injuries occurring in inflammatory disorders.

The total phenol test confirmed the presence of appreciable amounts of phenolics in HLE. The antioxidant activity of phenolic compounds is well known and is mainly due to their redox properties, which play an important role in neutralizing free radicals, quenching singlet and triplet oxygen species, or decomposing peroxides (Rice-Evans et al., 1996). Though the exact phytochemical constituents of HLE which showed in vitro antioxidant activity in this study is still unclear, phenolic compounds may be partly responsible.

\section{Conclusion}

It is clear from the study that HLE has anti-inflammatory activity in both acute and chronic inflammation models. HLE also has antioxidant activity, which may contribute to its anti-inflammatory activity.

\section{Acknowledgements}

The authors are grateful for the technical assistance offered by Mr. Thomas Ansah of the Department of Pharmacology, Faculty of Pharmacy and Pharmaceutical Sciences, KNUST, Kumasi.

\section{References}

1. Abotsi, W.K.M., Woode, E., Ainooson, G.K., Amo-Barimah, A.K. and Boakye-Gyasi, E. (2010). Antiarthritic and antioxidant effects of the leaf extract of Ficus exasperata P. Beauv.(Moraceae). Pharmacog. Res. 2: 89. 
2. Aebi, H. (1974). Catalase. In: H.U. Bergmeyer (Ed.), Methods of Enzymatic Analysis. Academic Press, New York. pp. 673-684.

3. Al-Turki, D.A., Abou-Zeid, L.A., Shehata, I.A. and Al-Omar, M.A. (2010). Therapeutic and toxic effects of new NSAIDs and related compounds: A review and prospective study. Int. J. Pharmacol. 6: 813-825.

4. Aota, S., Nakamura, T., Suzuki, K., Tanaka, Y., Okazaki, Y., Segawa, Y., Miura, M. and Kikuchi, S. (1996). Effects of indomethacin administration on bone turnover and bone mass in adjuvant-induced arthritis in rats. Calcif. Tissue Int. 59: 385-391.

5. Bae, S.C., Kim, S.J. and Sung, M.K. (2003). Inadequate antioxidant nutrient intake and altered plasma antioxidant status of rheumatoid arthritis patients. J. Am. Coll. Nutr. 22: 311-315.

6. $\quad$ Barbosa-Filho, J.M., Piuvezam, M.R., Moura, M.D., Silva, M.S., Lima, K.V.B., da-Cunha, E.V.L., Fechine, I.M. and Takemura, O.S. (2006). Anti-inflammatory activity of alkaloids: a twenty-century review. Rev. Bras. Farmacogn. 16: 109-139.

7. Blois, M.S. (1958). Antioxidant Determinations by the Use of a Stable Free Radical. Nature 181: 1199-1200.

8. Braddock, M. (2007). 11th annual Inflammatory and Immune Diseases Drug Discovery and Development Summit 12-13 March 2007, San Francisco, USA. Expert Opin. Investig. Drugs 16: 909-917.

9. $\quad$ Conforti, F., Sosa, S., Marrelli, M., Menichini, F., Statti, G.A., Uzunov, D., Tubaro, A. and Loggia, R.D. (2008). In

vivo anti-inflammatory and in vitro antioxidant activities of Mediterranean dietary plants. J. Ethnopharmacol. 116: 144-151.

10. Conner, E.M. and Grisham, M.B. (1996). Inflammation, free radicals, and antioxidants. Nutrition 12: 274-277.

11. Di Rosa, M., Giroud, J.P. and Willoughby, D.A. (1971). Studies on the mediators of the acute inflammatory response induced in rats in different sites by carrageenan and turpentine. J. Pathol. 104: 15-29.

12. Di Rosa, M. and Willoughby, D.A. (1971). Screens for anti-inflammatory drugs. J. Pharm. Pharmacol. 23: 297-298.

13. Dokosi, O.B. (1998). Herbs Of Ghana. Ghana Universities Press, Accra.

14. Donaldson, L.F., McQueen, D.S. and Seckl, J.R. (1995). Neuropeptide gene expression and capsaicin-sensitive primary afferents: maintenance and spread of adjuvant arthritis in the rat. J. Physiol. 486 ( Pt 2): 473-482.

15. Findlay, D.M. and Haynes, D.R. (2005). Mechanisms of bone loss in rheumatoid arthritis. Mod Rheumatol 15: 232-

240 .

16. Geronikaki, A.A. and Gavalas, A.M. (2006). Antioxidants and inflammatory disease: synthetic and natural antioxidants with anti-inflammatory activity. Comb. Chem. High Throughput Screen. 9: 425-442.

17. Guardia, T., Rotelli, A.E., Juarez, A.O. and Pelzer, L.E. (2001). Anti-inflammatory properties of plant flavonoids. Effects of rutin, quercetin and hesperidin on adjuvant arthritis in rat. Farmaco 56: 683-687.

18. He, Y.H., Zhou, J., Wang, Y.S., Xiao, C., Tong, Y., Tang, J.C., Chan, A.S. and Lu, A.P. (2006). Anti-inflammatory and anti-oxidative effects of cherries on Freund's adjuvant-induced arthritis in rats. Scand. J. Rheumatol. 35: 356-358.

19. Hoffmann, J.C., Herklotz, C., Zeidler, H., Bayer, B., Rosenthal, H. and Westermann, J. (1997). Initiation and perpetuation of rat adjuvant arthritis is inhibited by the anti-CD2 monoclonal antibody (mAb) OX34. Ann. Rheum. Dis. 56: 716-722.

20. Inatani, R., Nakatani, N. and Fuwa, H. (1983). Antioxidative Effect of the Constituents of Rosemary (Rosmarinus officinalis L.) and Their Derivatives. Agric. Biol. Chem. 47: 521-528

21. Jung, H.J., Nam, J.H., Choi, J., Lee, K.T. and Park, H.J. (2005). Antiinflammatory effects of chiisanoside and chiisanogenin obtained from the leaves of Acanthopanax chiisanensis in the carrageenan- and Freund's complete adjuvantinduced rats. J. Ethnopharmacol. 97: 359-367.

22. Kinne, R.W., Schmidt-Weber, C.B., Hoppe, R., Buchner, E., Palombo-Kinne, E., Nurnberg, E. and Emmrich, F. (1995). Long-term amelioration of rat adjuvant arthritis following systemic elimination of macrophages by clodronatecontaining liposomes. Arthritis Rheum. 38: 1777-1790.

23. Kitamura, T., Hashimoto, J., Murase, T., Tomita, T., Hattori, T., Yoshikawa, H. and Sugamoto, K. (2007). Radiographic study of joint destruction patterns in the rheumatoid elbow. Clin. Rheumatol. 26: 515-519.

24. Kolli, V.K., Abraham, P. and Isaac, B. (2007). Alteration in antioxidant defense mechanisms in the small intestines of methotrexate treated rat may contribute to its gastrointestinal toxicity. Cancer Ther. 5: 501-510.

25. Kumar, D.A., Manikandan, P., Sumitra, M., Raju, K.V., Gayathri, C., Arutselvan, N. and Puvanakrishnan, R. (2002). A novel peptide derivative exhibits anti inflammatory and antioxidant activity in adjuvant induced arthritis in rats. Mol. Cell. Biochem. 229: 9-17.

26. Lucas, R., Giannini, C., D'Auria M, V. and Paya, M. (2003). Modulatory effect of bolinaquinone, a marine sesquiterpenoid, on acute and chronic inflammatory processes. J. Pharmacol. Exp. Ther. 304: 1172-1180.

27. Mahajan, A. and Tandon, V.R. (2004). Antioxidants and rheumatoid arthritis. J Indian Rheumatol Assoc 12: 139-

142.

28. Miller, J.R. (2003). GraphPad Version 4.0. Step-by-Step Examples. GraphPad Software Inc., San Diego, CA:.

29. Misra, H.P. and Fridovich, I. (1972). The role of superoxide anion in the autoxidation of epinephrine and a simple assay for superoxide dismutase. J. Biol. Chem. 247: 3170-3175.

30. Motulsky, H.J. and Christopoulos, A. (2003). Fitting model to biological data using linear and nonlinear regression. A practical guide to curve fitting. GraphPad Software Inc, San Diego, CA.

31. Mshana, N.R., Abbiw, D.K., Addae-Mensah, I., Adjanohoun, E., Ahyi, M.R.A., Ekpere, J.A., Enow-Orock, E.G., Gbile, Z.O., Noamesi, G.K., Odei, M.A., Odunlami, H., Oteng-Yeboah, A.A., Sarpong, K., Soforowa, A. and Tackie, A.N. (2000). Traditional Medicine and Pharmacopoeia. Contribution to the Revision of Ethnobotanical and Floristic Studies in Ghana. Organization of African Unity/Scientific, Technical \& Research Commision, Accra.

32. Narendhirakannan, R.T., Subramanian, S. and Kandaswamy, M. (2005). Free radical scavenging activity of Cleome gynandra L. leaves on adjuvant induced arthritis in rats. Mol. Cell. Biochem. 276: 71-80. 
33. Orzechowski, A., Ostaszewski, R., Brodnicka, A., Wilczak, J., Jank, M., Balasinska, B., Grzelkowska, K., Ploszaj, T., Olczak, J. and Mrowczynska, A. (2000). Excess of Glucocorticoids Impairs Whole-Body Antioxidant Status in Young Rats. Relation to the Effect of Dexamethasone in Soleus Muscle and Spleen. Horm. Metab. Res. 32: 174-180.

34. Osterman, T., Kippo, K., Lauren, L., Hannuniemi, R. and Sellman, R. (1994). Effect of clodronate on established adjuvant arthritis. Rheumatol. Int. 14: 139-147.

35. Oyaizu, M. (1986). Studies on products of browning reaction: Antioxidative activities of products of browning reaction prepared from glucosamine. Jpn. J. Nutr 44: 307-315

36. Pearson, C.M. (1956). Development of arthritis, periarthritis and periostitis in rats given adjuvants. Proc. Soc. Exp. Biol. Med. 91: 95-101.

37. Prieto, P., Pineda, M. and Aguilar, M. (1999). Spectrophotometric Quantitation of Antioxidant Capacity through the Formation of a Phosphomolybdenum Complex:Specific Application to the Determination of Vitamin E. Anal. Biochem. 269: $337-341$

38. Rice-Evans, C.A., Miller, N.J. and Paganga, G. (1996). Structure-antioxidant activity relationships of flavonoids and phenolic acids. Free Radic. Biol. Med. 20: 933-956.

39. Roach, J.T. and Sufka, K.J. (2003). Characterization of the chick carrageenan response. Brain Res. 994: 216-225.

40. Schopf, L., Savinainen, A., Anderson, K., Kujawa, J., DuPont, M., Silva, M., Siebert, E., Chandra, S., Morgan, J., Gangurde, P., Wen, D., Lane, J., Xu, Y., Hepperle, M., Harriman, G., Ocain, T. and Jaffee, B. (2006). IKKbeta inhibition protects against bone and cartilage destruction in a rat model of rheumatoid arthritis. Arthritis Rheum. 54: 3163-3173.

41. Seibert, K., Zhang, Y., Leahy, K., Hauser, S., Masferrer, J., Perkins, W., Lee, L. and Isakson, P. (1994). Pharmacological and biochemical demonstration of the role of cyclooxygenase 2 in inflammation and pain. Proc. Natl. Acad. Sci. U.S.A. 91: 12013-12017.

42. Shah, B.N., Seth, A.K. and Maheshwari, K.M. (2011). A review on medicinal plants as a source of antiinflammatory agents. Res. J. Med. Plant. 5: 101-115.

43. Slinkard, K. and Singleton, V.L. (1977). Total phenol analyses:Automation and comparison with manual methods. Am. J. Enol. Vitic. 28: 49-55.

44. Thomazzi, S.M., Silva, C.B., Silveira, D.C., Vasconcellos, C.L., Lira, A.F., Cambui, E.V., Estevam, C.S. and Antoniolli, A.R. (2010). Antinociceptive and anti-inflammatory activities of Bowdichia virgilioides (sucupira). J. Ethnopharmacol. 127: 451-456.

45. Trease, G.E. and Evans, W.C. (1989). A Textbook of Pharmacognosy, 13th ed., Baillière Tindall, London.

46. van Eden, W., Holoshitz, J., Nevo, Z., Frenkel, A., Klajman, A. and Cohen, I.R. (1985). Arthritis induced by a Tlymphocyte clone that responds to Mycobacterium tuberculosis and to cartilage proteoglycans. Proc. Natl. Acad. Sci. U.S.A. 82: 5117-5120.

47. Vane, J.R. and Botting, R.M. (1995). A better understanding of anti-inflammatory drugs based on isoforms of cyclooxygenase (COX-1 and COX-2). Adv. Prostaglandin. Thromboxane. Leukot. Res. 23: 41-48.

48. Vijayalakshmi, T., Muthulakshmi, V. and Sachdanandam, P. (1997). Salubrious effect of Semecarpus anacardium against lipid peroxidative changes in adjuvant arthritis studied in rats. Mol. Cell. Biochem. 175: 65-69.

49. Vinegar, R., Schreiber, W. and Hugo, R. (1969). Biphasic development of carrageenin edema in rats. J. Pharmacol. Exp. Ther. 166: 96-103.

50. Whitehouse, M., Fairlie, D. and Thong, Y. (1994). Anti-inflammatory activity of the isoquinoline alkaloid, tetrandrine, against established adjuvant arthritis in rats. Inflamm. Res. 42: 123-127.

51. Winrow, V.R., Winyard, P.G., Morris, C.J. and Blake, D.R. (1993). Free radicals in inflammation: second messengers and mediators of tissue destruction. Br. Med. Bull. 49: 506-522.

52. Winter, C.A., Risley, E.A. and Nuss, G.W. (1962). Carrageenin-induced edema in hind paw of the rat as an assay for antiiflammatory drugs. Proc. Soc. Exp. Biol. Med. 111: 544-547.

53. Woode, E., Poku, R.A., Ainooson, G.K., Boakye-Gyasi, E., Abotsi, W.K.M., Mensah, T.L. and Amoh-Barimah, A.K. (2009). An evaluation of the anti-inflammatory, antipyretic and antinociceptive effects of Ficus exasperata (Vahl) leaf extract. J. Pharmaco. Toxicol. 4: 138-151. 